\title{
The cellular mechanisms of memory are modified by experience
}

\author{
Brian J. Wiltgen, ${ }^{1,3}$ Alynda N. Wood, ${ }^{1}$ and Brynne Levy ${ }^{2}$ \\ ${ }^{1}$ Department of Psychology, University of Virginia, Charlottesville, Virginia 22904, USA; ${ }^{2}$ Department of Biology, University of Virginia, \\ Charlottesville, Virginia 22904, USA
}

\begin{abstract}
The N-methyl-D-aspartate receptor (NMDAR) is thought to be essential for synaptic plasticity and learning. However, recent work indicates that the role of this receptor depends on the prior history of the research subject. For example, animals trained on a hippocampus-dependent learning task are subsequently able to acquire new information in the absence of NMDAR activation. The current experiments were designed to identify the types of experiences that lead to NMDAR-independent learning. Using contextual fear conditioning in mice, we find that NMDAR-independent learning is only observed when (1) animals are trained on the same behavioral task and (2) initial learning is successfully encoded into long-term memory.
\end{abstract}

[Supplemental material is available for this article.]

The cellular and molecular basis of memory has been thoroughly characterized in the hippocampus. Research indicates that Nmethyl-D-aspartate receptors (NMDARs) mediate learning by increasing calcium influx and initiating intracellular events that lead to gene expression and synaptic strengthening (Morris et al. 1990; Elgersma and Silva 1999). Similar mechanisms are important for learning and plasticity in a number of other brain systems including eyeblink conditioning in the cerebellum, fear learning in the amygdala, goal-directed learning in the striatum, and conditioned taste aversion in the insular cortex (Fanselow and Kim 1994; Rosenblum et al. 1997; Chen and Steinmetz 2000; Yin et al. 2005). As a result, it is widely believed that NMDAR-mediated plasticity is required for learning and memory. Despite these data, several studies indicate that prior behavioral experience can reduce or eliminate the need for NMDARs during learning. For example, animals trained on a hippocampusdependent learning task are subsequently able to acquire new information in the presence of NMDAR antagonists (Bannerman et al. 1995; Saucier and Cain 1995; Sanders and Fanselow 2003; Hardt et al. 2009; Wiltgen et al. 2010; Tayler et al. 2011). These results suggest that prior behavioral training modifies cellular plasticity mechanisms such that NMDARs are no longer required for learning.

The current experiments examined the features of prior experience that are necessary to produce NMDAR-independent context fear conditioning. It is possible that this novel type of learning only occurs when animals are repeatedly trained on the same behavioral task. In our previous experiments, for example, mice underwent fear conditioning in two different contexts (Wiltgen et al. 2010; Tayler et al. 2011). In the Morris water maze, NMDAR-independent learning was observed when rats were trained on the same version of the task in two different spatial environments (Bannerman et al. 1995). Based on these results, one could conclude that the NMDAR is necessary to learn the basic rules or framework of a specific task (Bannerman et al. 1995; Sanders and Fanselow 2003). Once this framework has been established, the NMDAR is not necessary for subsequent

\section{${ }^{3}$ Corresponding author.}

E-mail bw4fh@virginia.edu.

Article is online at http://www.learnmem.org/cgi/doi/10.1101/Im.024026.111. learning on the same task. An alternative idea is that all hippocampus-dependent behavioral tasks initiate cellular changes that reduce the contribution of NMDARs to subsequent learning. According to this account, animals would not need to be trained on the same behavioral task to show NMDAR-independent learning. Instead, both tasks would simply need to engage synaptic plasticity mechanisms in the hippocampus. To test between these possibilities, we gave mice one of several behavioral experiences prior to context fear conditioning.

Our previous results indicate that context fear can be acquired in the absence of NMDAR activation in previously trained mice (Wiltgen et al. 2010; Tayler et al. 2011). In these experiments, animals were fear-conditioned in context $\mathrm{B}$ followed $5 \mathrm{~d}$ later by training in context $\mathrm{A}$. Infusions of the NMDAR antagonist APV into the hippocampus blocked conditioning in context B but had no effect on subsequent learning in context A. Intraperitoneal (IP) injections of the NMDAR antagonist CPP produced the same effect. These data indicate that NMDAR activation is required for initial learning in context $\mathrm{B}$, but not subsequent learning in context $\mathrm{A}$. The current experiments examined the impact of several different learning experiences on the development of NMDAR-independent context fear conditioning. Four groups of mice received unique training experiences and were then fear-conditioned in context A the following day (Fig. 1). These included Morris water maze training, context conditioning, and immediate shock training. Thirty minutes before training in context $\mathrm{A}$, mice received an injection of saline or CPP (10 mg/kg; Sigma-Aldrich). Memory was tested the following day by measuring the freezing response during a 5-min context test (Anagnostaras et al. 2010).

Group MWM was first trained on the spatial version of the Morris water maze. These animals learned to find a hidden platform across five training days (main effect of day, $F_{(4,52)}=9.97$, $P<0.05$; no effect of group, $F<1$; no day $\times$ group interaction, $\left.F_{(4,52)}=1.19, P>0.05\right)$ and showed selective searching in the target quadrant during the probe test (main effect of quadrant, $F_{(1,13)}=38.57, P<0.05$; no effect of group, $F_{(1,13)}=1.37, P>$ 0.05 ; no quadrant $\times$ group interaction, $F_{(1,13)}=1.37, P>0.05$ ) (Fig. 2A,B). Group B-A was fear-conditioned in context B prior to training in context A. Previous work from our lab showed that this experience leads to NMDAR-independent learning (Wiltgen 


\begin{tabular}{|c|c|c|}
\hline Group & 1st experience & 2nd experience \\
\hline Control & Nothing & Train A \\
\hline MWM & MWM & Train A \\
\hline B-A & Train B & Train A \\
\hline $\mathrm{mm}$ B-A & Immed shk B & Train A \\
\hline
\end{tabular}

Figure 1. Four groups of mice were used to examine the effects of prior experience on NMDAR-independent context fear learning. The control group received no prior experience, the MWM group was trained on the hidden version of the water maze, group B-A was fear-conditioned in context B, and Imm B-A received immediate shocks in context $B$. One day after these experiences, the mice received injections of saline or CPP and were trained in context $A$ ( $N$ 's for saline/CPP groups; control $=5 / 6, \mathrm{MWM}=7 / 8, \mathrm{~B}-\mathrm{A}=8 / 8, \mathrm{Imm} \mathrm{B}-\mathrm{A}=6 / 6$ ).

et al. 2010; Tayler et al. 2011). Group Imm B-A was fear-conditioned in context B using an immediate shock procedure prior to training in context A. Shock was presented $5 \mathrm{sec}$ after placement in the conditioning chamber, which does not provide adequate time to learn about the context (Fanselow 1990; Wiltgen et al. 2001; Frankland et al. 2004). As a result, this group should not form a memory of context $\mathrm{B}$ and can be used to determine if exposure to footshock is sufficient to produce NMDARindependent context fear learning in context A.

Figure $2 \mathrm{C}$ shows the amount of baseline freezing in context $\mathrm{A}$ prior to shock delivery in saline-injected animals. As expected, there was very little baseline freezing in the control, MWM, and Imm B-A groups. Relative to these mice, group B-A showed elevated freezing (main effect of group, $F_{(3,22)}=5.96, P<0.05$; Fisher's protected least significant difference (PLSD) post hoc comparisons, $P$-values $<0.05)$. This result is consistent with previous work and indicates that prior learning in context B produces a small amount of fear generalization to context A (Hardt et al. 2009; Tayler et al. 2011). The fact that group B-A froze significantly more than animals in group Imm B-A indicates that immediate shock prevented mice from learning about context B.

Twenty-hour hours after training in context $\mathrm{A}$, mice received a test in the same environment (Fig. 2D). A set of planned comparisons (Fisher's PLSD) revealed that CPP impaired memory for context $\mathrm{A}$ in all groups $(P$-values $<0.05)$ except group B-A $(P>0.05)$. Control mice that received injections of $\mathrm{CPP}$ showed significantly less context fear than saline-injected animals, as observed previously (Wiltgen et al. 2010; Tayler et al. 2011). A similar deficit was observed in CPP-injected mice that had undergone water maze training. This result indicates that prior spatial learning in the Morris water maze is not sufficient to produce NMDAR-independent context fear conditioning. Consistent with previous results, mice that were initially fear-conditioned in context $\mathrm{B}$ learned normally in context $\mathrm{A}$ even in the presence of CPP (Wiltgen et al. 2010; Tayler et al. 2011). Together, these results
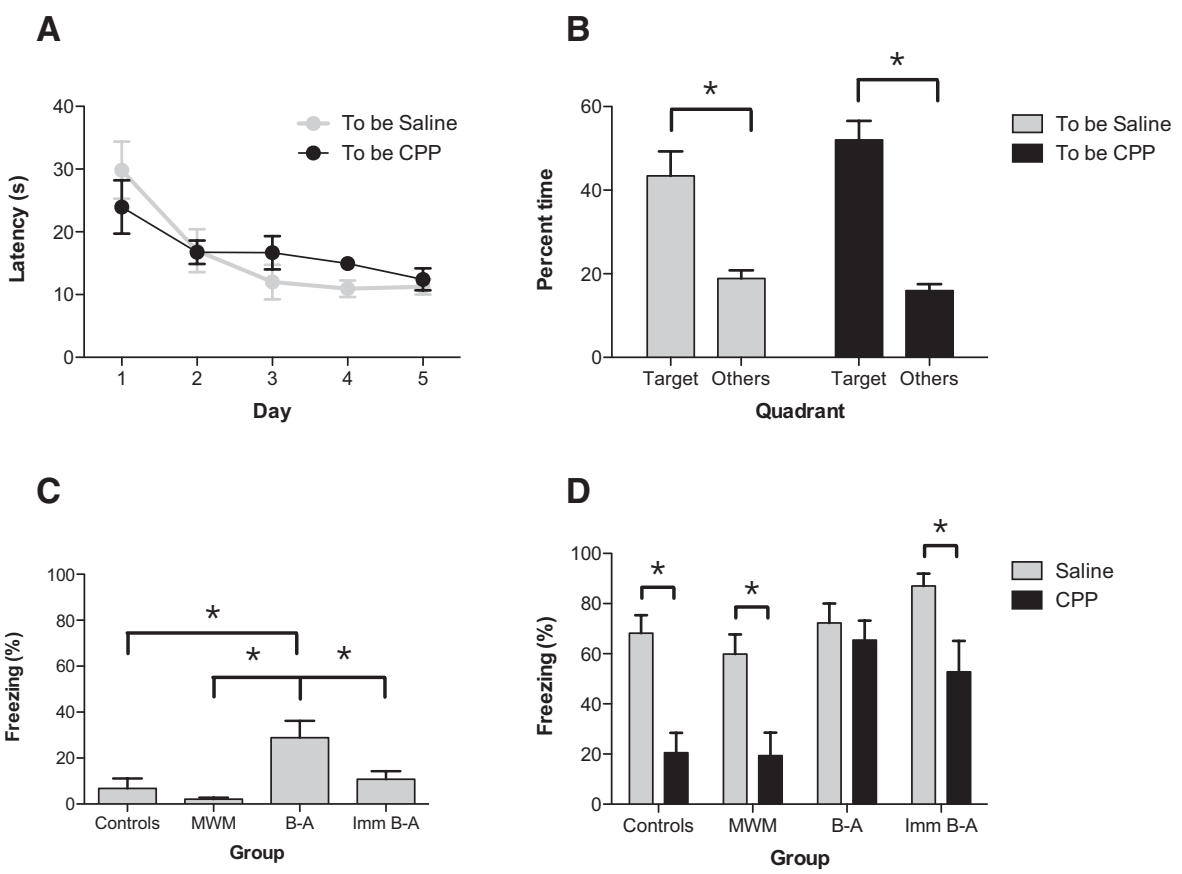

Figure 2. (A) Both groups of mice trained in the Morris water maze learned to find the hidden platform across five training days. (B) Spatial memory was assessed on day 6 by removing the platform and conducting a probe test. Both groups of mice searched selectively in the target quadrant where the platform had been located during training. (C) Baseline freezing prior to shock presentation in context A. Group B-A showed elevated freezing relative to all other groups, indicating a small amount of generalization between context $B$ and context $A$. $(D)$ Freezing during the memory test in context A. CPP injections during training in context $\mathrm{A}$ impaired memory for this context in all groups except B-A. In all panels, error bars represent SEM. $\left.{ }^{*}\right) P<0.05$. 
A

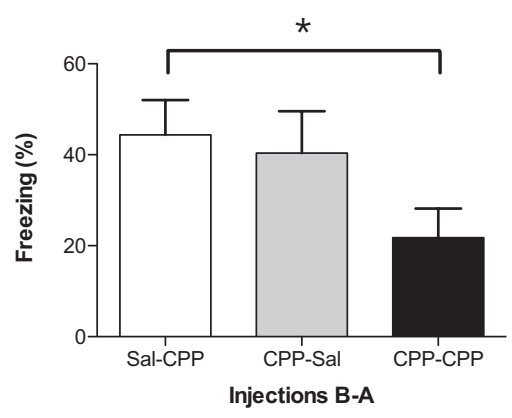

B

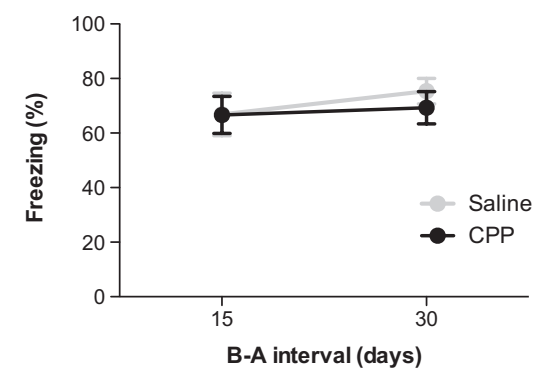

Figure 3. ( $A$ ) Mice received injections of saline or CPP prior to initial conditioning in context $\mathrm{B}$ and subsequent learning in context $A$. Three groups of mice were examined (context B injection-context A injection): Saline-CPP $(n=10)$, CPP-saline $(n=8)$, and CPP-CPP $(n=10)$. Memory for context A was tested on day 3. Group CPP-CPP showed reduced freezing relative to the other groups. However, only the difference between saline-CPP and CPP-CPP groups reached statistical significance. (B) Mice were trained in context B followed $15 \mathrm{~d}$ or $30 \mathrm{~d}$ later by conditioning in context $\mathrm{A}$. Injections of CPP prior to training in context $\mathrm{A}$ had no effect in either group $(n=10$ for all groups). In all panels, error bars represent SEM. (*) $P<0.05$.

CPP-CPP groups $(P<0.05)$ and a marginally significant difference between CPP-saline and CPP-CPP groups $(P=0.1)$. These results indicate that learning about context $\mathrm{B}$ is required for NMDAR-independent to occur in context A. If learning about context $\mathrm{B}$ is blocked with CPP then mice are subsequently impaired by an injection of CPP in context A. A similar result was previously observed using the protein synthesis inhibitor anisomycin to block initial context learning (Hardt et al. 2009).

The existing data indicate that NMDAR-independent learning is observed for several days after context fear conditioning (Sanders and Fanselow 2003; Hardt et al. 2009; Wiltgen et al. 2010; Tayler et al. 2011). It is possible that this effect is transient and fades over time. If this is the case, then increasing the interval between training in context $\mathrm{B}$ and training in context A should reinstate the effectiveness of $\mathrm{CPP}$. In contrast, if prior conditioning produces a long-lasting effect on cellular plasticity mechanisms then CPP will continue to be ineffective even at longer intervals. The current experiment examined this idea by conditioning mice in context B followed 15 or $30 \mathrm{~d}$ later by training in context A (Fig. 3B). Injections of saline or CPP were administered $30 \mathrm{~min}$ before training in context $\mathrm{A}$. We found that injections of CPP had no effect on learning in context A 15 or $30 \mathrm{~d}$ after training in context B (no effect of drug, $F<1$; no effect of day, $F<1$; no drug $\times$ day interaction, $F<1$ ). Therefore, fear conditioning produces a long-lasting change in the cellular mechanisms that are used to encode new information. There is some evidence that context fear memories can be retrieved without the hippocampus 1 month after learning (Kim and Fanselow 1992; Anagnostaras et al. 1999). However, other studies indicate that retrieval of these memories always requires the hippocampus (Sutherland et al. 2008). The current experiment did not examine this issue. As a result, we do not know if memory for context B influenced subsequent learning via hippocampal and/or neocortical circuitry.

The current study adds to a growing literature indicating that experienced animals can learn in the presence of NMDAR antagonists (Bannerman et al. 1995; Saucier and Cain 1995; Sanders and Fanselow 2003; Chan and McNally 2009; Hardt et al. 2009; Langton and Richardson 2009, 2010; Wiltgen et al. 2010; Tayler et al. 2011). We found that mice fear-conditioned in context $B$ were subsequently able learn about context $A$ in the presence of CPP. This result implies that prior experience modifies the cellular mechanisms that are used to encode new information. However, this effect is only observed when mice were retrained on the same behavioral task. Animals that were first trained in the Morris water maze did not subsequently show NMDAR-independent context fear learning. This finding demonstrates that prior spatial learning is not sufficient to produce NMDAR-independent context fear conditioning. Instead, animals must be repeatedly trained on the same behavioral task in order to learn without NMDARs.

The existing data suggest that the NMDAR plays a selective role in learning the basic rules or framework of a new task (Bannerman et al. 1995; Sanders and Fanselow 2003). Once this framework has been acquired, animals can learn the same task in a new environment without activating NMDARs. In the Morris water maze the rules are quite clear; find a hidden platform that is located in a fixed spatial position. Once learned, it is easy to see how this information could transfer to a new environment. Context fear conditioning, in contrast, is Pavlovian in nature and does not require the learning of any explicit rules (Bolles and Riley 1973). Nonetheless, it is possible that forming an expectation of shock could generalize to a new environment and lead to NMDAR-independent learning. This does not appear to be the case, however, as simply exploring context B (in the absence of shock) is enough to produce subsequent NMDAR-independent learning in context A (Tayler et al. 2011). Based on these data, we argue that forming a representation of the initial training environment is the critical factor that allows subsequent learning to occur in the absence of NMDAR activation. Once a representation of the environment is formed, it can be transferred to a similar context and modified in an NMDARindependent manner. If a new environment is sufficiently dissimilar from previously experienced ones (e.g., water maze vs. fear conditioning chamber) then NMDARs are once again required for learning.

In order for existing memory representations to influence later learning they must be reactivated in new contexts. Several pieces of data suggest that this is the case. In a previous study we used TetTag mice to permanently label hippocampal neurons activated by context fear conditioning with a long-lasting green fluorescent protein (GFP). When mice were subsequently trained in a new context, a number of these same neurons were reactivated (Tayler et al. 2011). Similarly, a recent electrophysiological study showed that previously learned spatial sequences are spontaneously replayed in the hippocampus when animals explore a new environment (Karlsson and Frank 2009). It is therefore possible that stored representations are used as templates in new environments that can be modified via NMDAR-independent plasticity mechanisms.

The cellular mechanisms that mediate NMDAR-independent learning are currently unknown. Likely candidates include receptor proteins that are upregulated by experience and contribute to synaptic plasticity. Calcium-permeable (CP) AMPARs, for example, are expressed in hippocampal neurons following fear learning and can mediate NMDAR-independent long-term potentiation (LTP) (Jia et al. 1996; Wiltgen et al. 2010; Mitsushima et al. 2011). In addition, conditional knockout mice that express high levels of $\mathrm{CP}$-AMPARs in the CA1 region of the hippocampus are able to acquire context fear in an NMDAR-independent fashion (Wiltgen et al. 2010). These data raise the possibility that CP- 
AMPARs mediate learning in the absence of NMDAR activation. However, a recent study found that expression of CP-AMPARs after fear conditioning was transient and, as we show in the current paper, NMDAR-independent learning is still observed several weeks after initial learning (Mitsushima et al. 2011). Therefore, future studies will need to identify changes in synaptic plasticity mechanisms that are induced by prior learning and stable over long periods of time.

\section{Acknowledgments}

This work was supported by a Jeffress Memorial Trust research grant to B.J.W.

\section{References}

Anagnostaras SG, Maren S, Fanselow MS. 1999. Temporally graded retrograde amnesia of contextual fear after hippocampal damage in rats: Within-subjects examination. J Neurosci 19: 1106-1114.

Anagnostaras SG, Wood SC, Shuman T, Cai DJ, Leduc AD, Zurn KR, Zurn JB, Sage JR, Herrera GM. 2010. Automated assessment of Pavlovian conditioned freezing and shock reactivity in mice using the video freeze system. Front Behav Neurosci 4: 158. doi: 10.3389/fnbeh.200.00158.

Bannerman DM, Good MA, Butcher SP, Ramsay M, Morris RG. 1995. Distinct components of spatial learning revealed by prior training and NMDA receptor blockade. Nature 378: 182-186.

Bolles RC, Riley AL. 1973. Freezing as an avoidance response: Another look at the operant-respondent distinction. Learn Motiv 4: 268-275.

Chan WY, McNally GP. 2009. Conditioned stimulus familiarity determines effects of MK-801 on fear extinction. Behav Neurosci 123: 303-314.

Chen G, Steinmetz JE. 2000. Intra-cerebellar infusion of NMDA receptor antagonist AP5 disrupts classical eyeblink conditioning in rabbits. Brain Res 887: 144-156.

Elgersma Y, Silva AJ. 1999. Molecular mechanisms of synaptic plasticity and memory. Curr Opin Neurobiol 9: 209-213.

Fanselow MS. 1990. Factors governing one-trial contextual conditioning. Anim Learn Behav 18: 264-270.

Fanselow MS, Kim JJ. 1994. Acquisition of contextual Pavlovian fear conditioning is blocked by application of an NMDA receptor antagonist D,L-2-amino-5-phosphonovaleric acid to the basolateral amygdala. Behav Neurosci 108: 210-212.

Frankland PW, Josselyn SA, Anagnostaras SG, Kogan JH, Takahashi E, Silva AJ. 2004. Consolidation of CS and US representations in associative fear conditioning. Hippocampus 14: 557-569.
Hardt O, Wang SH, Nader K. 2009. Storage or retrieval deficit: The yin and yang of amnesia. Learn Mem 16: 224-230.

Jia Z, Agopyan N, Miu P, Xiong Z, Henderson J, Gerlai R, Taverna FA, Velumian A, MacDonald J, Carlen P, et al. 1996. Enhanced LTP in mice deficient in the AMPA receptor GluR2. Neuron 17: 945-956.

Karlsson MP, Frank LM. 2009. Awake replay of remote experiences in the hippocampus. Nat Neurosci 12: 913-918.

Kim JJ, Fanselow MS. 1992. Modality-specific retrograde amnesia of fear. Science 256: 675-677.

Langton JM, Richardson R. 2009. The role of context in the re-extinction of learned fear. Neurobiol Learn Mem 92: 496-503.

Langton JM, Richardson R. 2010. The temporal specificity of the switch from NMDAr-dependent extinction to NMDAr-independent re-extinction. Behav Brain Res 208: 646-649.

Mitsushima D, Ishihara K, Sano A, Kessels HW, Takahashi T. 2011. Contextual learning requires synaptic AMPA receptor delivery in the hippocampus. Proc Natl Acad Sci 108: 12503-12508.

Morris RG, Davis S, Butcher SP. 1990. Hippocampal synaptic plasticity and NMDA receptors: A role in information storage? Philos Trans $R$ Soc Lond B Biol Sci 329: 187-204.

Rosenblum K, Berman DE, Hazvi S, Lamprecht R, Dudai Y. 1997. NMDA receptor and the tyrosine phosphorylation of its $2 \mathrm{~B}$ subunit in taste learning in the rat insular cortex. J Neurosci 17: 5129-5135.

Sanders MJ, Fanselow MS. 2003. Pre-training prevents context fear conditioning deficits produced by hippocampal NMDA receptor blockade. Neurobiol Learn Mem 80: 123-129.

Saucier D, Cain DP. 1995. Spatial learning without NMDA receptordependent long-term potentiation. Nature 378: 186-189.

Sutherland RJ, O'Brien J, Lehmann H. 2008. Absence of systems consolidation of fear memories after dorsal, ventral, or complete hippocampal damage. Hippocampus 18: 710-718.

Tayler KK, Lowry E, Tanaka K, Levy B, Reijmers L, Mayford M, Wiltgen BJ. 2011. Characterization of NMDAR-independent learning in the hippocampus. Front Behav Neurosci 5: 28. doi: 10.3389/fnbeh.2011. 00028.

Wiltgen BJ, Sanders MJ, Behne NS, Fanselow MS. 2001. Sex differences, context preexposure, and the immediate shock deficit in Pavlovian context conditioning with mice. Behav Neurosci 115: 26-32.

Wiltgen BJ, Royle G, Gray EE, Abdipranoto A, Thangthaeng N, Jacobs N, Saab F, Tonegawa S, Heinemann SF, O'Dell TJ, et al. 2010. A role for calcium-permeable AMPA receptors in synaptic plasticity and learning. PLoS One 5: e12818. doi: 10.1371/journal.pone.0012818.

Yin HH, Knowlton BJ, Balleine BW. 2005. Blockade of NMDA receptors in the dorsomedial striatum prevents action-outcome learning in instrumental conditioning. Eur J Neurosci 22: 505-512.

Received August 24, 2011; accepted in revised form October 6, 2011. 


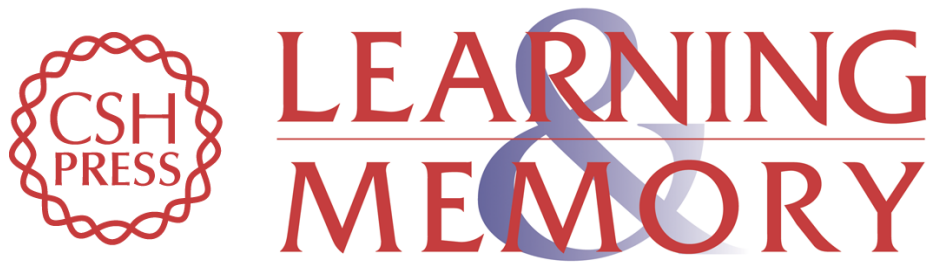

\section{The cellular mechanisms of memory are modified by experience}

Brian J. Wiltgen, Alynda N. Wood and Brynne Levy

Learn. Mem. 2011, 18:

Access the most recent version at doi:10.1101//m.024026.111

Supplemental http://learnmem.cshlp.org/content/suppl/2011/11/15/18.12.747.DC1

References This article cites 26 articles, 5 of which can be accessed free at: http://learnmem.cshlp.org/content/18/12/747.full.html\#ref-list-1

License

Email Alerting Receive free email alerts when new articles cite this article - sign up in the box at the Service top right corner of the article or click here. 